Article

\title{
An Enhanced Emulated Inertia Control for Grid-Connected PV Systems with HESS in a Weak Grid
}

\author{
Ratnam Kamala Sarojini $^{1}{ }^{\mathbb{D}}$, Palanisamy Kaliannan ${ }^{1}$, Yuvaraja Teekaraman ${ }^{2} \mathbb{D}$, Srete Nikolovski ${ }^{3, * \mathbb{D}}$ \\ and Hamid Reza Baghaee 4 (i)
}

1 Vellore Institute of Technology, School of Electrical Engineering, Vellore 632 014, Tamil Nadu, India; ratnamkamala.sarojini2017@vitstudent.ac.in (R.K.S.); kpalanisamy@vit.ac.in (P.K.)

2 EVERGi-Sustainable Energy Communities, MOBI-Mobility, Logistics and Automotive Technology Research Centre, ETEC-Department of Electrical Engineering and Energy Technology, Faculty of Engineering, Vrije Universiteit Brussel, 1050 Brussel, Belgium; Yuvaraja.teekaraman@vub.be

3 Power Engineering Department, Faculty of Electrical Engineering, Computer Science and Information Technology, University of Osijek, 31000 Osijek, Croatia

4 Department of Electrical Engineering, Amirkabir University of Technology, Tehran 15875-4413, Iran; hrbaghaee@aut.ac.ir

* Correspondence: srete.nikolovski@ferit.hr

Citation: Sarojini, R.K.; Kaliannan, P.; Teekaraman, Y.; Nikolovski, S.;

Baghaee, H.R. An Enhanced

Emulated Inertia Control for Grid-Connected PV Systems with HESS in a Weak Grid. Energies 2021, 14, 1721. https://doi.org/10.3390/ en14061721

Academic Editor: S. M. Muyeen

Received: 3 February 2021

Accepted: 16 March 2021

Published: 19 March 2021

Publisher's Note: MDPI stays neutral with regard to jurisdictional claims in published maps and institutional affiliations.

Copyright: (c) 2021 by the authors. Licensee MDPI, Basel, Switzerland. This article is an open access article distributed under the terms and conditions of the Creative Commons Attribution (CC BY) license (https:/ / creativecommons.org/licenses/by/ $4.0 /)$.

\begin{abstract}
The role of renewable energy sources in the power grid is increasing tremendously. However, power electronic converters are used to incorporate RES into the grid without inertia. This article recommends an improved emulated inertia control approach focused on the frequency deviation and rate of change of frequency to enhance the inertia of a power system. The required inertial power calculated from emulated inertia control is delivered through hybrid energy storage systems equipped with a proper hybrid energy storage system control. The fast-varying power calculated from emulated inertia control is linked to super-capacitor. Simultaneously, the battery handles the slow varying power by regulating the DC bus voltage proportionate to the frequency variations. Further, the stability of the emulated inertia control and hybrid energy storage system controller is validated by Bode plots. The simulation results verified the correctness of the proposed emulated inertia control and hybrid energy storage system control. The real-time simulation results with the help of OPAL-RT are presented to validate the proposed method's feasibility.
\end{abstract}

Keywords: inertia emulation; hybrid energy storage systems; frequency control; grid-connected PV; super-capacitor; battery

\section{Introduction}

Recently, electricity generation from renewable energy sources (RES) is growing due to environmental protection rules and to improve energy conservation [1]. The rise in the electricity generation from power electronic converter-based RES does not possess inertia without a proper control technique. As a consequence, the system inertia continues to decrease. In a conventional power system, kinetic energy stored in the synchronous generator (SG) plays an important role in the inertial response. When a frequency event occurs, the SG adjusts the rotational speed depending on its inertia [2,3]. The phenomenon of low inertia in a weak grid results in two significant challenges under frequency events. The first challenge refers to a high rate of change of frequency (ROCOF), that may result in protective relay tripping, and the same has been identified by the Irish grid operators [4]. The second challenge is that large frequency deviations may cause load shedding and cascading failure [5].

Various solutions to deal with low inertia issues in power systems have already been anticipated in the literature. A simple solution is to adjust the ROCOF's specifications to withstand generator capabilities [6], although the high ROCOF standards impact the 
generator losses. Usage of synchronous compensators in a weak grid is an alternative approach for solving low-inertia problems [7]. However, the high installation cost of these rotating stabilizers limits their usage.

Various emulated inertia control techniques were anticipated in the literature for the power electronic converters to mimic the inertial characteristics of the SG [8-11]. These techniques mainly focus on the control design and rarely discuss their practical implementation. An evolving concept for implementing frequency regulation is acknowledged as emulated inertia control (EIC) in this paper. The EIC approach is a suitable answer for the low-inertia system. In [12], the study evaluated the small-signal investigation of EIC implemented at ideal grid-connected inverter. Nevertheless, previous investigation on EIC mainly emphasis on the controller design and few researchers confer the functional implementation of EICs. Apart from the EIC, the de-loading control method for PV systems for controlling the frequency and offering an inertial response is proposed in [13,14]. However, the PV modules are forced to function below the maximum power-point.

In [15-17], the authors proposed inertia emulation by regulating the charging and discharging of the DC link capacitors. The DC link voltage reference is modified to inject/absorb inertial power for frequency deviations. The inertia emulation through the capacitor is relatively efficient. However, it is only applicable to the systems where the variations in the DC link voltage are allowed. The electrochemical storage devices are the most useful technology in grid-connected RES systems to balance the power. In [18-21], the authors used batteries to inject/absorb the power in the inertial response, but the usage of low-power density batteries to withstand the high-power peaks is not adequate as it reduces the battery's lifespan.

Furthermore, the performance of super-capacitor (SC) in the inertial response is satisfactory. In [22-24] the SC's usage in the inertial response is proposed, although, the aggregate of battery and SC is taken into consideration because of its advantages: decreases the battery size, increases the battery's lifespan, provides the inertial response, and higher system efficiency [25]. In hybrid energy storage systems (HESS), the SC is utilized to supply a highly variable power component, and the battery is used to handle the slowly variable power component. Inertia emulation for a rooftop PV inverter is anticipated in [26]. In [27], the HESS is used to regulate the frequency using a virtual synchronous generator, however, the frequency deviation alone is considered in this emulation technique. Both parameters (frequency deviation and ROCOF), which influence the frequency stability, must be regarded as improving the power system's inertia.

Hence, this article proposes EIC that considers frequency deviation as well as ROCOF. The frequency regulation from the proposed EIC is simple and straightforward; the required inertia calculated from the EIC is supplied/absorbed by the HESS. The modified HESS control technique is proposed in this article to proportionally correlate the grid frequency variation to the DC bus voltage. The stability of the proposed EIC and HESS control is evaluated with Bode plots. This paper explores the grid frequency support support offered by grid-connected PV-HESS system with the EIC technique's help.

The remainder of this article is arranged as follows: Section 2 discusses the system architecture, Section 3 defines the control schematic of the proposed EIC and modified HESS control, Section 4 outlines the stability analysis of EIC and HESS controllers to demonstrate the efficacy of the proposed EIC and HESS techniques, simulation results are provided in Section 5, real-time simulation results for the proposed EIC are deliberated in Section 6; Section 7 gives the conclusions of this article.

\section{System Architecture}

The grid-connected PV-HESS considered in this article is illustrated in Figure 1. The $\mathrm{PV}$ array is attached to the DC bus through the DC-DC converter. It aims to obtain the available power from the PV array by using maximum power point technique (MPPT). The three-phase inverter converts the DC to AC, and it is coupled to the grid with an LCL filter. The purpose of the filter is to remove high switching frequency components 
from the inverter current. The battery and SC are associated to the DC bus with a bidirectional converter. Battery supplies/handles the slowly variable power, whereas the SC supply/handle the sudden power surges. Figure 1 consists of three power stages, and which are shown below:

- PV system with a boost converter.

- HESS unit with bidirectional DC-DC converters.

- Three-phase inverter with LCL filter.

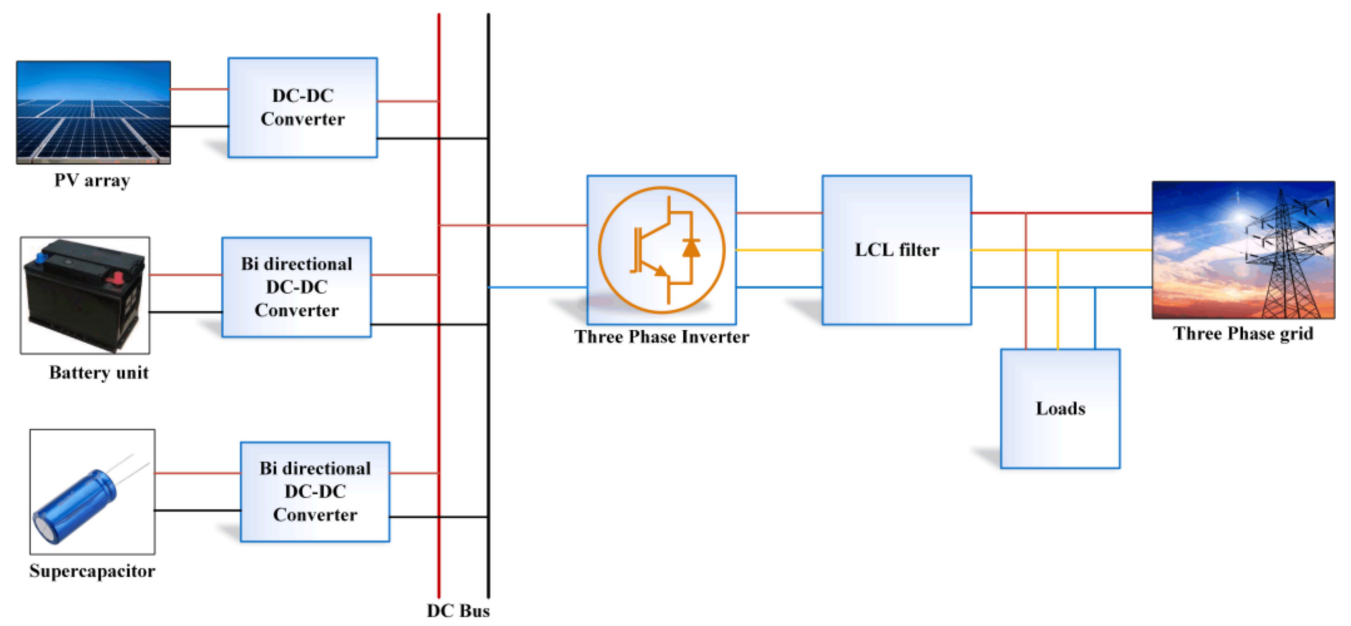

Figure 1. Grid-connected PV-HESS structure.

\subsection{PV Array with Boost Converters}

In this paper, the power generating capacity of $10 \mathrm{~kW}$ PV array is considered. The configuration of the PV array circuit is shown in Figure 2. A DC-DC converter is utilised to connect the PV array to the DC bus. It utilizes a simple P \& O MPPT to obtain optimum power from the PV. The P \& O algorithm slightly alters voltage and investigates whether output power increased or not. The operating voltage does not change when there is no rise in the power from the PV array.

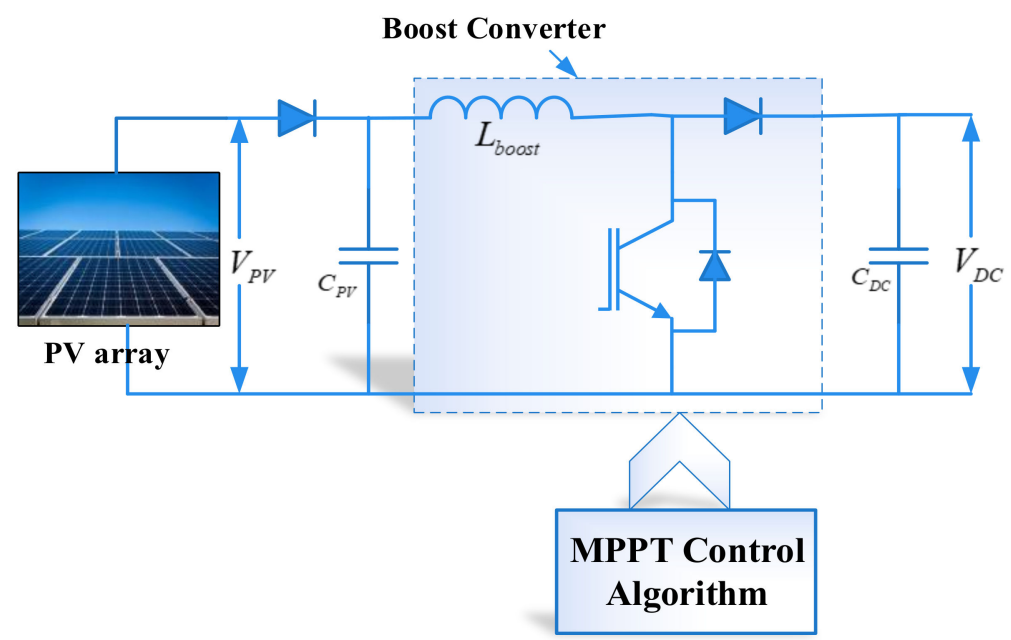

Figure 2. PV array with a boost converter.

\subsection{HESS Unit with Bidirectional DC-DC Converters}

The PV arrays are working at the optimum power point to extract the power under variations in irradiation and temperature. However, there is no reserve power available at the PV system to regulate the frequency under power imbalances. Generally, the PV systems are configured with the battery alone. Hence the battery used to injects/absorbs 
the power under imbalances. If the power imbalance occurs abruptly and consistently, then the battery is charged and discharged regularly. This influences the stress on the battery and impacts the lifespan. Hence, SC is coupled to the DC bus for offering the inertial response. SCs respond sooner than a battery to counteract the frequency deviations. The key reasons behind the deploying of HESS in PV systems are: (i) to offset the reduced inertia and (ii) to balance the generation and demand. The HESS is coupled to the DC bus by bi-directional converters, as seen in Figure 3 .

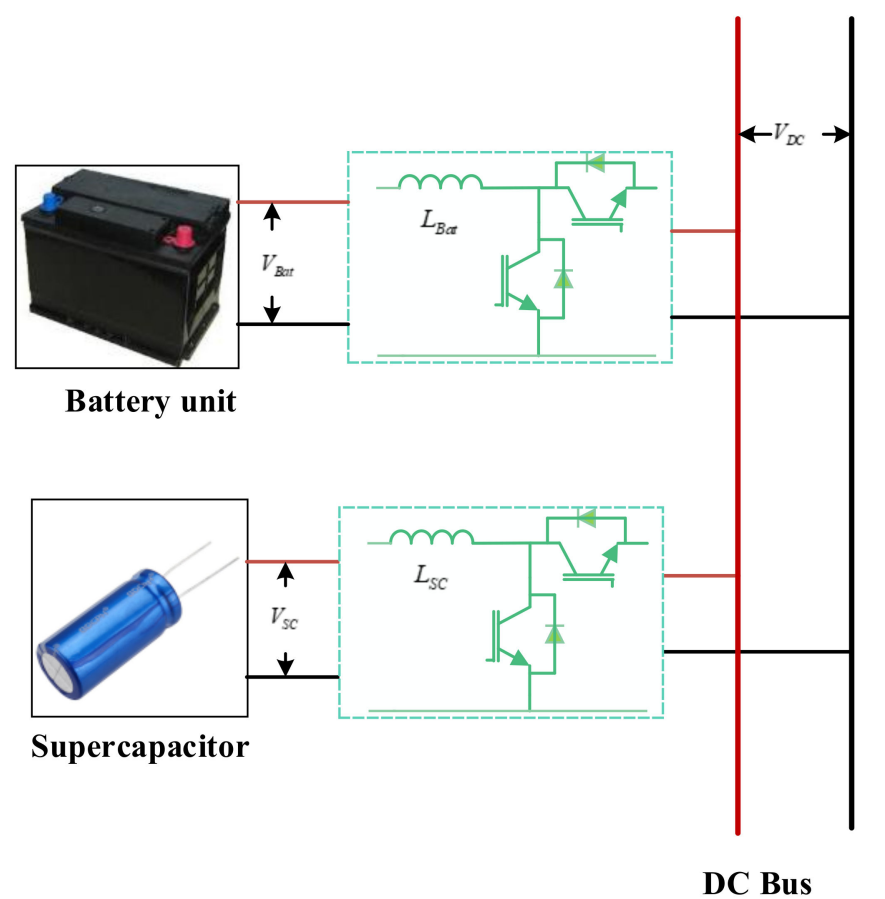

Figure 3. Hybrid energy storage system (battery and supercapacitor) connected to DC-Bus.

Inertia Provided by SC

The inertia constant provided by SC is derived. The SC can handle the sudden power variations. A assessment may be found among the power in SC and the kinetic energy in SG.

During power imbalance, the swing equation can be written as [23]:

$$
\frac{2 H}{\omega_{g 0}} \frac{d \omega_{g}}{d t}=\Delta P
$$

The power drawn from SC under power imbalance:

$$
\frac{C_{S C} V_{S C}}{S_{P V}} \frac{d V_{S C}}{d t}=\Delta P
$$

The inertia constant $H_{S C}$ can be derived by equating (1) and (2):

$$
\frac{2 H_{S C}}{\omega_{g 0}} \frac{d \omega_{g}}{d t}=\frac{C_{S C} V_{S C}}{S_{P V}} \frac{d V_{S C}}{d t}
$$

After integrating on both sides of (3):

$$
\frac{2 H_{S C}}{\omega_{g 0}} \omega_{g}=\frac{C_{S C} V_{S C}^{2}}{2 S_{P V}}+K_{1}
$$

where $K_{1}$ is the integration constant $=2 H_{S C}-\frac{C_{S C} V_{S C 0}^{2}}{2 S_{P V}}$. 
The inertia constant realised from the SC is:

$$
H_{S C}=\frac{C_{S C} \omega_{g 0} V_{S C 0} \Delta V_{S C, \max }}{2 S_{P V} \Delta \omega_{g, \max }}
$$

\subsection{Three Phase Inverter with LCL Filter}

The power electronic inverter, along with the LCL filter, is used as an interface between the DC bus and the grid, as shown in Figure 4. The filter is helped to reduce the harmonic content. The ripple current and operating voltage are considered when designing the filter [28]. The maximum rated power capacity chooses the rating of the inverter switches. The switching pulses of the three-phase inverter are generated using the EIC discussed in Section 3.

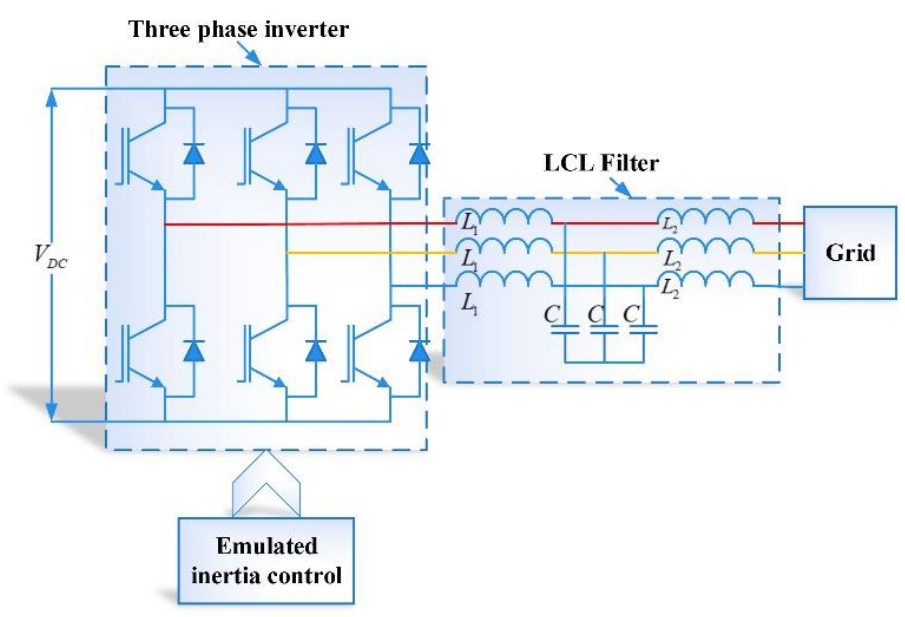

Figure 4. Three-phase inverter with LCL filter.

The EIC applied to the inverter inject/absorb the power on sudden load variations to decrease the frequency nadir. The HESS at the DC bus takes care of frequency deviations. The detailed description of the DC voltage controller of the battery and EIC of the inverter is discussed in Section 3.

\section{Control Schematic}

This section describes the proposed emulated inertia control, followed by the HESS controller to support the inertia.

\subsection{Proposed Emulated Inertia Control}

The active power through HESS is proportionally linked to the grid frequency variations by using the proposed EIC and HESS control. The inertia is emulated for the PV-HESS system, contributes to enhancing the inertial response of the power system under power imbalances. The active power required for inertial response calculated in this paper includes two control loops, and it is shown in Figure 5. The fundamental idea of the proposed EIC is shown in Figure 6. The first loop of the power signal is proportional to the frequency deviation. In contrast, the second loop of the inertia power signal is proportional to the ROCOF. A dead band of $\pm 0.015 \mathrm{~Hz}$ is used to prevent the noisy signal from the ROCOF loop. The time constant of low pass filters in Figure 5 is selected to eliminate the power oscillations due to noise. 


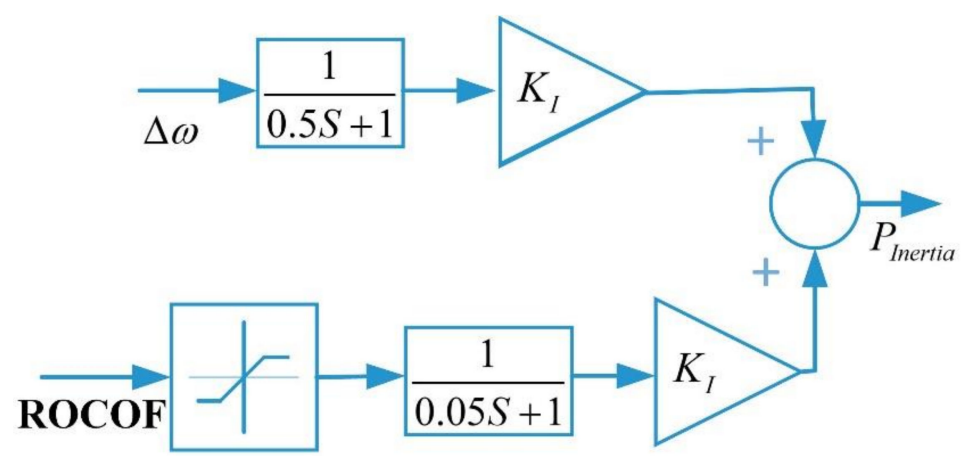

Figure 5. The required inertial power calculation block.

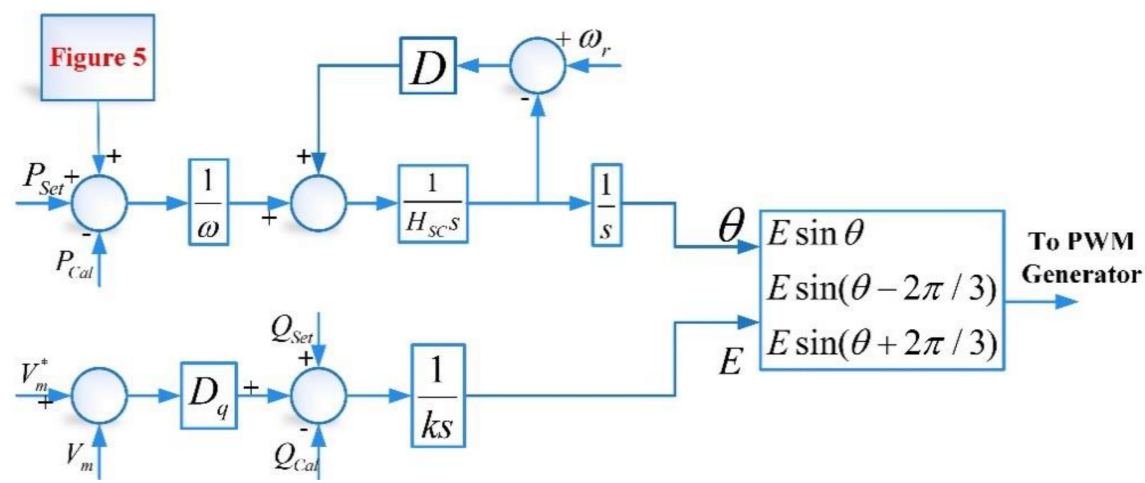

Figure 6. Proposed emulated inertia control.

When the frequency deviation occurs, the extra inertial response signal $P_{\text {Inertia }}$ is applied to the active power set point $P_{\text {set }}$. The $P_{\text {Inertia }}$ estimated from the ROCOF and frequency deviation loops as seen in Figure 5. The two loops have different effects on enhancing frequency stability. The ROCOF loop works when a ROCOF is very high. On the other hand, the frequency deviation loop plays an essential role in inertia regulation as the system frequency goes up or down significantly.

The appropriate inertial active power from Figure 5:

$$
P_{\text {Inertia }}=K_{D} \Delta f+K_{I} \frac{d f}{d t}
$$

The necessary emulation power determined from Figure 5 is added to the EIC to alter the load angle under frequency deviations. The reactive power loop of the EIC adjusts the voltage.

The following equations described the core algorithm of the proposed EIC:

In the vector control, a phase locked loop is required to estimate the frequency and phase-angle:

$$
\begin{gathered}
\left(P_{\text {Set }}-P_{\text {Cal }}+P_{\text {Inertia }}\right) / \omega-D\left(\omega-\omega_{r}\right)=2 H_{S C} \frac{d \omega}{d t} \\
\frac{1}{k} \int\left(Q_{\text {Set }}-Q_{\text {Cal }}+D_{q}\left(V_{m}^{*}-V_{m}\right)\right) d t=E
\end{gathered}
$$

Basically, the PLL works on two roles: first, synchronization with the grid. Second, after synchronization, the PLL is responsible for the estimation of grid voltage frequency and angle. At the same time, the EIC technique applied in this paper has inherent synchronization capability and able to measure frequency. Hence the external PLL element is not used in this paper.

In the initial synchronization process, the power calculated from Figure 5 is used to regulate the torque from the drooping coefficient $(D)$ to be zero and to generate the frequency $(\omega)$. The drooping voltage coefficient $\left(D_{q}\right)$ is used to control the voltage magnitude. 
After the synchronization process is completed, the active power loop aims to supply the emulated power under imbalances.

In active power loop of EIC, the Inertia coefficient $\left(H_{S C}\right)$ is calculated from Equation (5) and the $(D)$ value is chosen to get the required time constant $\left(\tau_{a}=H_{S C} / D\right)$. In the reactive power loop the voltage drooping coefficient $\left(D_{q}\right)$ and integral gain $(k)$ is chosen to achieve the required time constant $\left(\tau_{r}=D_{q} / k\right)$.

It is necessary to choose appropriate values of $K_{I}$ and $K_{D}$. Else, it results in instability. $K_{I}$ is proportionate to ROCOF loop, $K_{D}$ is the gain of frequency deviation loop. A high $K_{I}$ and $K_{D}$ values lead to over-discharging of SC. An appropriate selection of the these two values leads to sufficient inertial response. Optimal values of $K_{I}$ and $K_{D}$ depend upon the maximum allowable ROCOF, frequency deviation, and maximum inertial power supplied from the system.

\subsection{Modified HESS Control}

The HESS control applied for this paper is shown in Figure 7. The association among the frequency and DC bus voltage is made in HESS controller to decrease in frequency spike in the recovery process. The required inertial power calculated from Figure 5 is considered to calculate the necessary inertial current released/absorbed from the HESS. The inertial reference current is added to the reference current calculated from the PI control. Using a low pass filter, the slowly varying component is supplied by the battery. The highly varying current handled by SC. The HESS controller consists of an outer voltage control loop and the inner current control loop. The outer voltage loop along with the inertia signal generates the reference current sufficient to counteract the power imbalance. The inner current control loop generates the pulses for the respective converters.

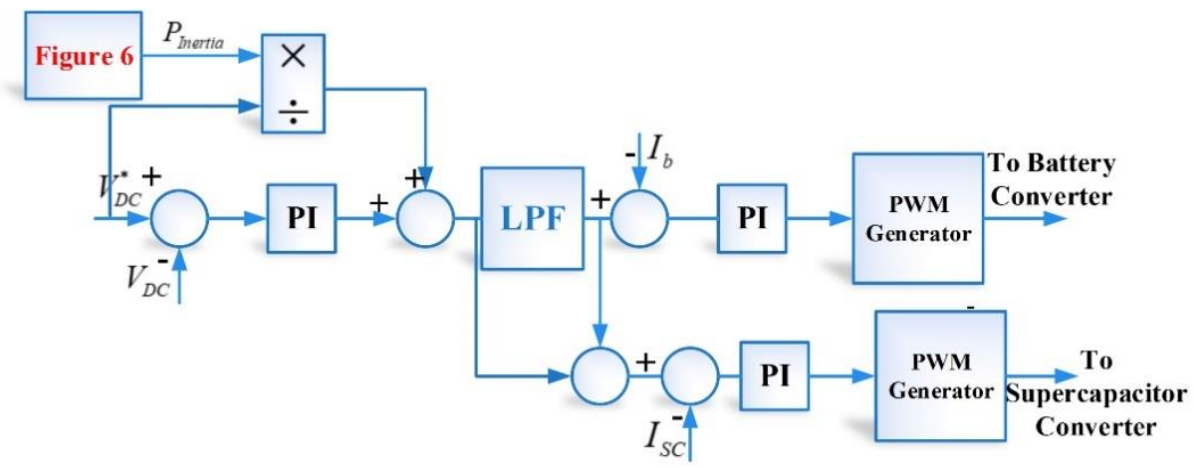

Figure 7. Hybrid energy storage system controller.

\section{Stability Analysis of Control System}

\subsection{Proposed EIC Control Design}

The purpose of this article is to control the frequency. Figure 8 illustrates the small signal modelling of EIC.

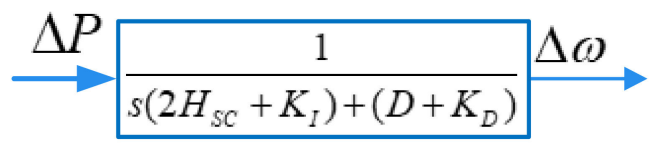

Figure 8. Simplified small-signal diagram of EIC.

The transfer function for change in angle to power given as:

$$
G_{p \theta}(s)=\frac{1}{\left(2 H_{S C}+K_{I}\right) s^{2}+\left(D+K_{D}\right) s}
$$

Figure 9 confirms the stability of EIC with a Bode plot. The EIC parameters are adjusted to attain the phase margin of 56 deg at infinite gain margin. 


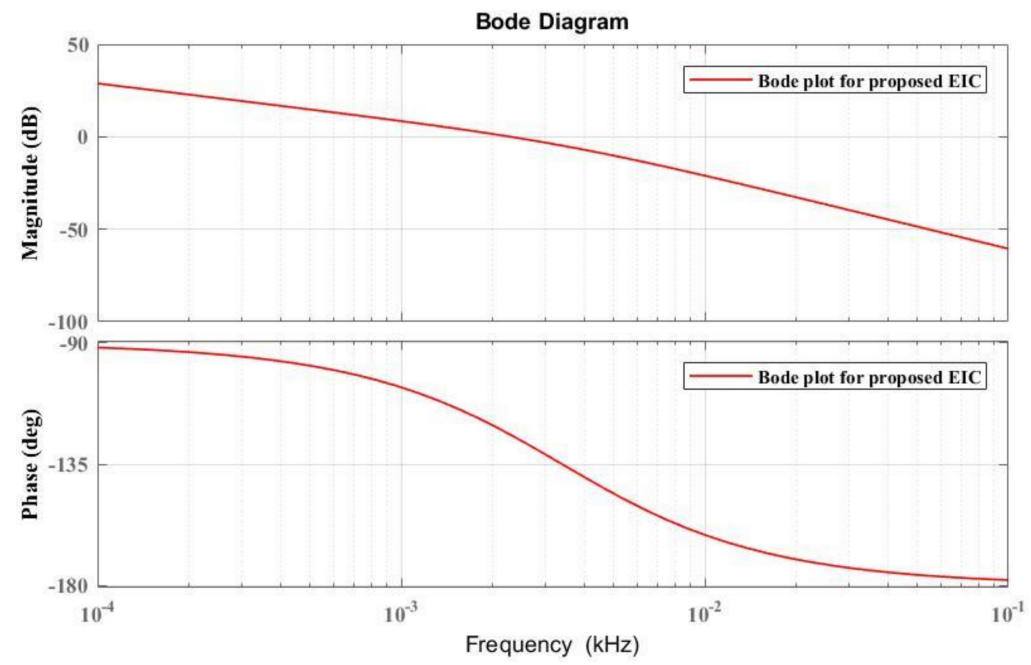

Figure 9. Bode plot for proposed EIC.

The frequency variation for an imbalance is expressed as:

$$
\Delta \omega=\frac{1}{\left(2 H_{S C}+K_{I}\right) s+\left(D+K_{D}\right)} \Delta P
$$

The frequency deviation at that instant after imbalance based on the initial value theorem as:

$$
\Delta \omega(0)=\lim _{s \rightarrow \infty} s \Delta \omega=\frac{\Delta P}{2 H_{S C}+K_{I}}
$$

It is evident that the frequency deviation at that instant is proportionate to the power imbalance and inversely proportionate to inertia.

Similarly, the steady-state frequency deviation after an imbalance can be obtained by using final value theorem:

$$
\Delta \omega(\infty)=\lim _{s \rightarrow 0} s \Delta \omega=0
$$

From (12), it is clear that the inertia has no effect on the steady-state frequency.

\subsection{HESS Control Design}

The small-signal model of the HESS controller is shown in Figure 10. The bi-directional converters connected in among the DC bus and energy storage device (battery and SC) are designed for boost mode of operation as used in [29].

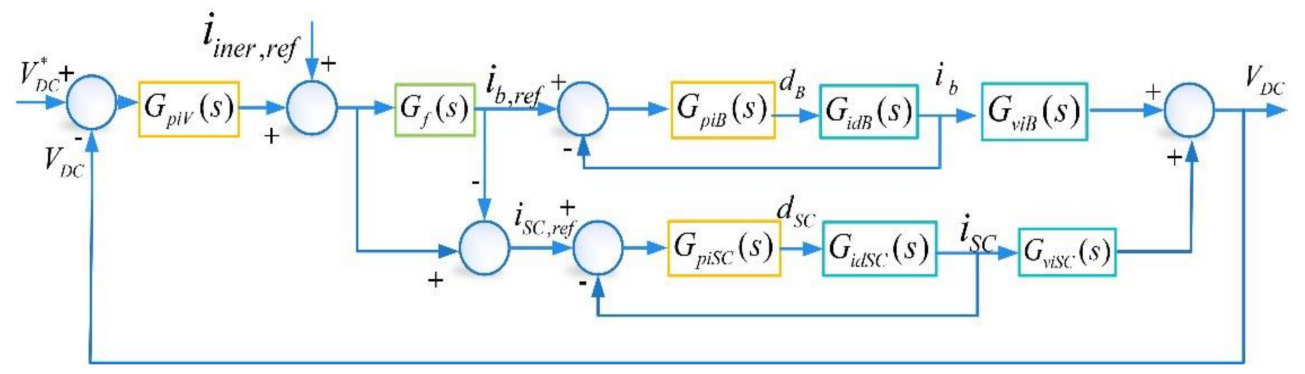

Figure 10. Small signal model of HESS controller.

\subsubsection{Design of Current Control Loop of Battery and SC}

The reference currents of the battery $\left(I_{b, r e f}\right)$ and SC $\left(I_{S C, r e f}\right)$ are generated from the voltage control loop, as shown in Figure 10. The reference currents are fed as input to the current control loop of each converter. The duty ratio $\left(\hat{d}_{B}(s) / \hat{d}_{S C}(s)\right)$ to the current $\left(\hat{i}_{B}(s) / \hat{i}_{S C}(s)\right)$ transfer function is shown in (13). To calculate the transfer function for the 
battery suffix, 'B' has to choose for all parameters, whereas for the SC suffix, 'SC' has to be chosen in (13):

$$
G_{i d B / i d S C}(s)=\frac{\hat{i}_{B / S C}(s)}{\hat{d}_{B / S C}(s)}=\frac{2 V_{d c}}{R_{L} D_{B / S C}^{2}} \frac{1+\frac{s}{\omega_{z i B / z i S C}}}{1+\frac{s}{Q_{B / S C} \omega_{0 B / O S C}}+\frac{s^{2}}{\omega_{0 B / O S C}^{2}}}
$$

where $\omega_{z i B / z i S C}=\frac{2}{R_{L} C_{d c}}, Q_{B / S C}=D_{B / S C} R_{L} \sqrt{\frac{C_{d c}}{L_{B / S C}}}$ and $\omega_{0 B / 0 S C}=\frac{D_{B / S C}}{\sqrt{L_{B / S C} C_{d c}}}$.

The transfer function of the battery/SC current controller is given by (14):

$$
G_{p i B / p i S C}=K_{p B / p S C}+\frac{K_{i B / i S C}}{s}
$$

The open-loop transfer function of the current control loop of the battery is:

$$
G_{o l \_B}=G_{p i B} G_{i d B}
$$

The open-loop transfer function of the current control loop of the SC is:

$$
G_{o l \_S C}=G_{p i S C} G_{i d S C}
$$

Figure 11 shows the uncompensated and compensated current control Bode plots for the battery and SC. The PI controllers of the battery and SC are designed to achieve the phase margin of 60 degrees at the infinite gain margin.

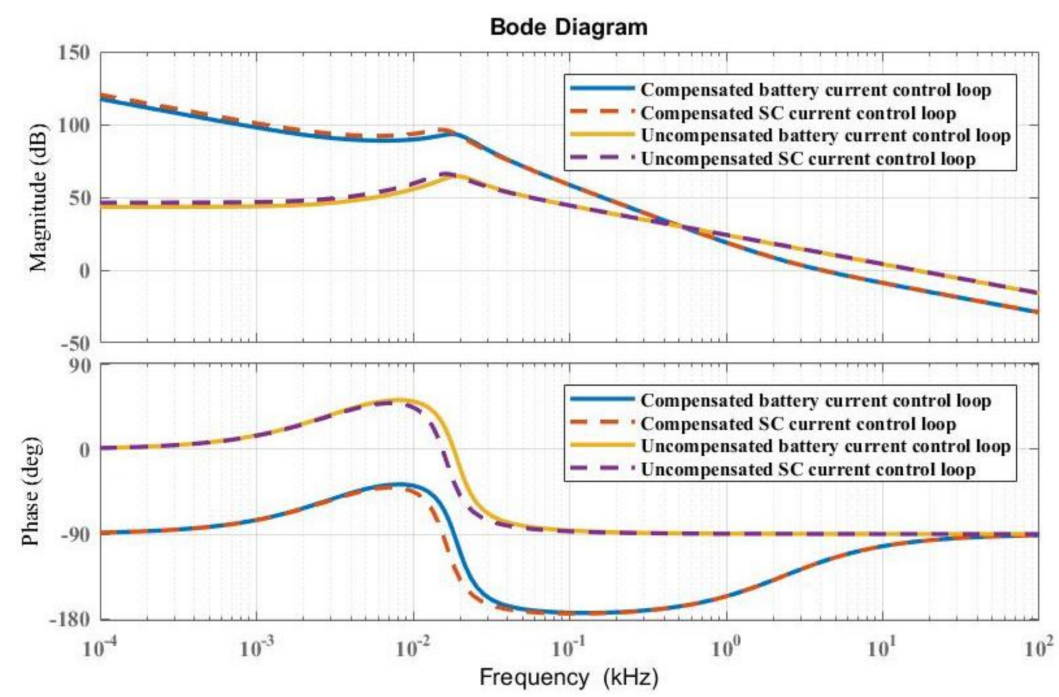

Figure 11. Bode plot of the compensated and uncompensated current control loop for battery and SC.

\subsubsection{Design of Voltage Control Loop of HESS}

Both the DC bus voltage and frequency deviations are considered in the voltage control loop of HESS. The low pass filter transfer function used in the voltage control loop of HESS is $G_{f}(s)=(1+s \tau)^{-1}$. In this paper voltage control loop of HESS is designed by considering the inner current loop of the battery. The transfer function for the battery current to the DC bus voltage is shown in (17):

$$
G_{v i B}(S)=\frac{\hat{v}_{d c}(s)}{\hat{i}_{B}(s)}=\frac{D_{B} R_{L}}{2} \frac{1-\frac{s}{\omega_{z v B}}}{1+\frac{s}{\omega_{p v B}}}
$$

where $\omega_{z v B}=\frac{D_{B}^{2} R_{L}}{L_{B}}$ and $\omega_{p v B}=\frac{2}{R_{L} C_{d c}}$. 
The transfer function of the voltage control loop of HESS is given by (18):

$$
G_{p i V}=K_{p v}+\frac{K_{i v}}{s}
$$

The open loop transfer function voltage control loop of HESS is:

$$
G_{o l_{-} V}=G_{p i V} G_{c l_{-} B} G_{v i B}
$$

Figure 12 shows the uncompensated and compensated voltage control Bode plots for HESS control. The PI. Controller of the voltage control is designed to attain phase margin of 74 degrees at infinite gain margin.

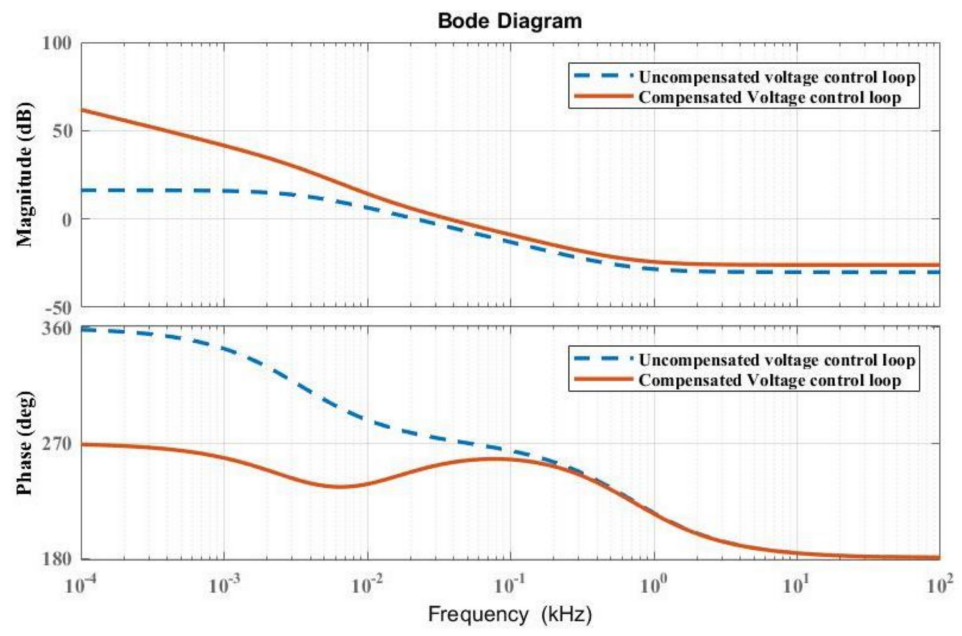

Figure 12. Bode plot for uncompensated and compensated voltage control loop of HESS.

\section{Simulation Results}

The proposed EIC with HESS in grid-connected PV system shown in Figure 1 is used for the frequency analysis. A series of simulations are carried out in MATLAB/Simulink on different cases to verify the proposed EIC's effectiveness with HESS in a grid-connected PV system. The detailed simulation parameters are tabulated in Table 1.

\subsection{Scenario 1: Performance Comparison of Proposed EIC under Load Transition}

In this section, the objective is to assess the performance of the proposed EIC during load transition. Primarily, the constant load of $8 \mathrm{~kW}$ is attached for a certain time. A sudden increase in the load is modeled at $t=2 \mathrm{~s}$ to produce an imbalance, leading to frequency deviations. From Figure 13, the frequency nadir of the system arrested at $49.781 \mathrm{~Hz}$ when EIC considered with the frequency deviation loop alone. The frequency nadir is limited to $49.786 \mathrm{~Hz}$ when EIC is considered both frequency deviation and ROCOF loops (without considering the interaction between the frequency deviation to the DC bus voltage in HESS control). The EIC technique, which considers two the loops is performed better than the EIC with frequency deviation to improve the frequency nadir. However, both EIC techniques resulted in a frequency spike in the retrieval process. The EIC with the HESS controller, supress the frequency spike in the retrieval process. The EIC control, along with HESS control not only restricts the frequency nadir but also reduces the ROCOF is illustrated in Figure 13a. The deviations in DC bus voltage and the active power output of the inverter under load transition is shown in Figure 13b,c. Table 2 summarizes the frequency deviation, ROCOF, DC bus voltage, and inverter output power for the different EIC strategies. 
Table 1. Simulation and real-time simulation parameters.

\begin{tabular}{|c|c|}
\hline Parameters & Values \\
\hline Reference frequency $(f)$ & $50 \mathrm{~Hz}$ \\
\hline Reference Voltage $\left(V^{*}\right)$ & $220 \mathrm{~V}$ \\
\hline Rated DC bus voltage $\left(V_{D C}\right)$ & $500 \mathrm{~V}$ \\
\hline PV cell & $\begin{array}{c}V_{O C}=37.3 \mathrm{~V}, I_{S C}=8.2 \mathrm{~A}, V_{m}=30.3 \text { unit?, } I_{m}= \\
7.5, N_{S}=10, N_{p}=5 .\end{array}$ \\
\hline Boost converter inductor & $5 \mathrm{mH}$ \\
\hline Boost converter capacitor & $200 \mu \mathrm{F}$ \\
\hline Rating of battery unit & $35 \mathrm{Ah}$ \\
\hline Battery terminal voltage & $250 \mathrm{~V}$ \\
\hline Supercapacitor & $0.8 \mathrm{~F}, 220 \mathrm{~V}$ \\
\hline DC bus capacitor & $3300 \mu \mathrm{F}$ \\
\hline Voltage controller (PI) & $K_{p v}=0.58, K_{i v}=4.8$ \\
\hline Current controller (PI) & $K_{p B / p S C}=2.1, K_{i b / i S C}=12.5$ \\
\hline Inverter side inductance $\left(L_{1}\right)$ & $2.5 \mathrm{mH}$ \\
\hline Load inductance $\left(L_{2}\right)$ & $0.83 \mathrm{mH}$ \\
\hline Filter capacitance $(C)$ & $12.0 \mu \mathrm{F}$ \\
\hline Frequency Drooping Coefficient $(D)$ & 50.0 \\
\hline Inertia coefficient $\left(H_{S C}\right)$ & 2.8 \\
\hline Voltage drooping coefficient $\left(D_{q}\right)$ & 120.0 \\
\hline Gain $(k)$ & 1000 A. s \\
\hline Inertial constant $\left(K_{I}\right)$ & 45.56 \\
\hline Damping constant $\left(K_{D}\right)$ & 1220 \\
\hline Load 1 & $8000 \mathrm{~W}$ \\
\hline Load 2 & $6000 \mathrm{~W}$ \\
\hline
\end{tabular}

Table 2. Performance comparison of different EIC strategies under sudden load increase.

\begin{tabular}{cccc}
\hline Parameter & $\begin{array}{c}\text { EIC with Frequency } \\
\text { Deviation Only }\end{array}$ & $\begin{array}{c}\text { Proposed EIC } \\
\text { without HESS } \\
\text { Control }\end{array}$ & $\begin{array}{c}\text { Proposed EIC with } \\
\text { HESS Control }\end{array}$ \\
\hline Frequency nadir $(\mathrm{Hz})$ & 49.81 & 49.790 & 49.78 \\
\hline ROCOF $(\mathrm{Hz} / \mathrm{s})$ & 0.265 & 0.242 & 0.202 \\
\hline DC bus voltage $(\mathrm{V})$ & 492.9 & 487.9 & 487 \\
\hline $\begin{array}{c}\text { Power supplied from } \\
\text { inverter during } \\
\text { inertial response }(\mathrm{kW})\end{array}$ & 12.13 & 12.52 & 12.51 \\
\hline
\end{tabular}




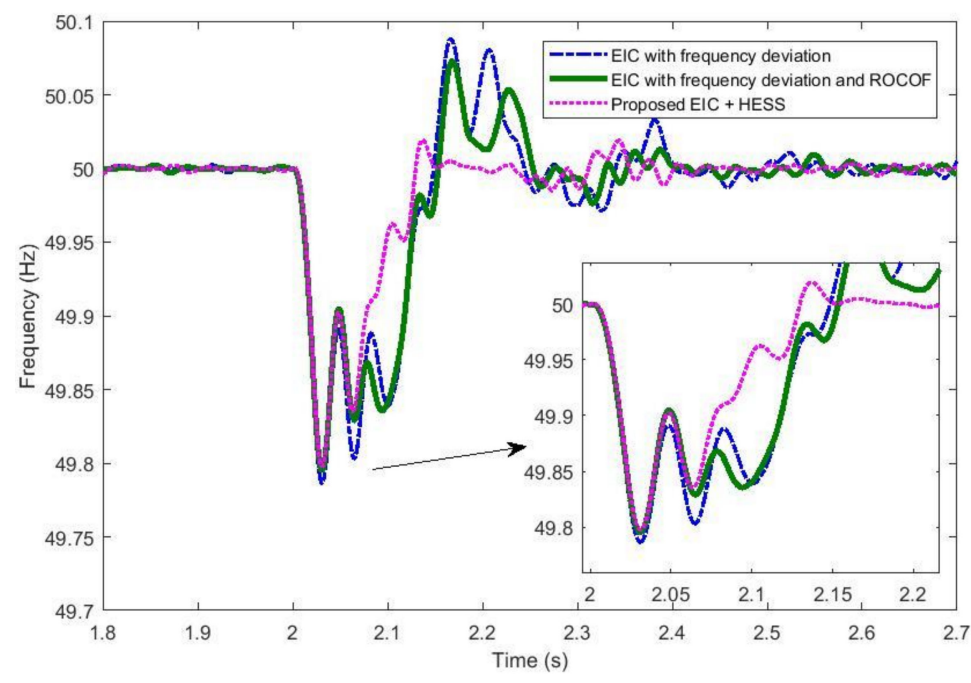

(a)

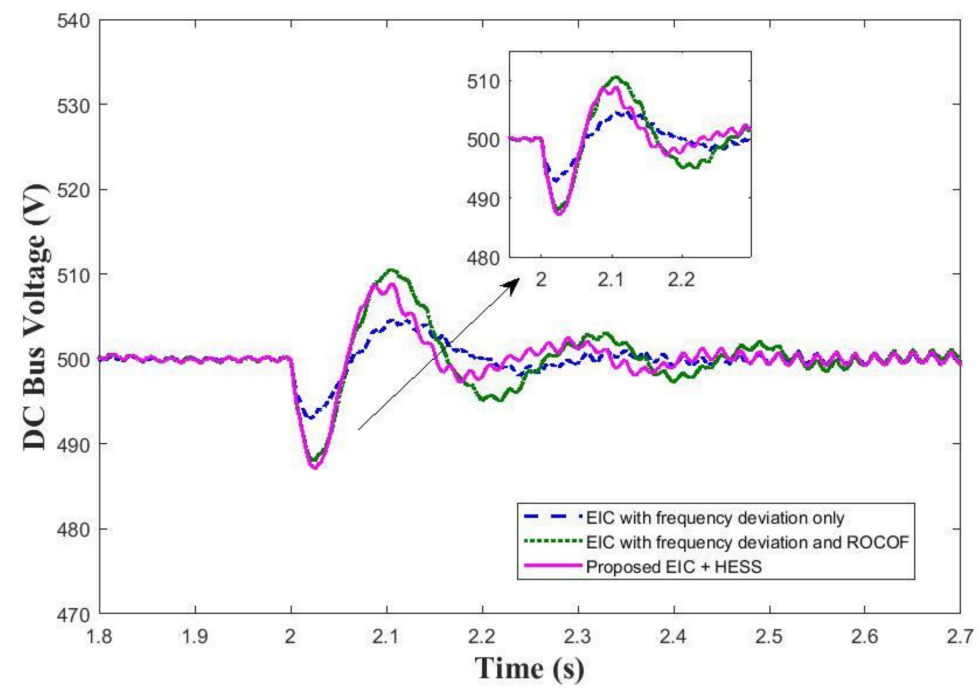

(b)

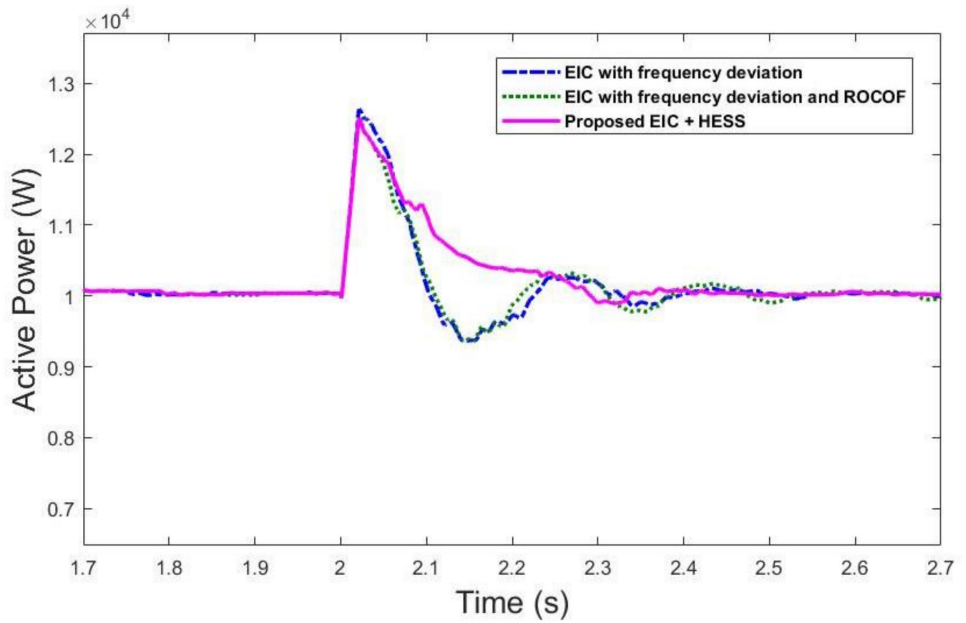

(c)

Figure 13. Performance verification with different EIC strategies; (a) frequency, (b) DC bus voltage, (c) Active power injected from grid-connected PV inverter. 


\subsection{Scenario 2: Performance of Proposed EIC under Real Power Setpoint Variations}

In this scenario, the $\mathrm{PV}$ is operating at constant irradiation of $1000 \mathrm{~W} / \mathrm{m}^{2}$ and generates an active power of 10,000 $\mathrm{W}$. The active power supplied by the three-phase inverter is a combination of PV and HESS as per the real power setpoint $\left(P_{S e t}\right)$ by the grid. The active power variations of PV, HESS, grid, frequency, and DC bus voltage is shown in Figure 14. Initially, the real power setpoint $\left(P_{\text {set }}\right)$ by the grid is $8500 \mathrm{~W}$. In this situation the excess power generated by the PV is absorbed by the battery. At $t=2 \mathrm{~s}$ a step increase in the real power set point from $8500 \mathrm{~W}$ to $10,000 \mathrm{~W}$ is observed from Figure 14. In this situation, the excess power at point of common coupling is injected into grid. The rapid imbalance in the active power will create a deviation in the frequency. At $t=4 \mathrm{~s}$, the sudden decrease in the real power set point from 10,000 $\mathrm{W}$ to $5000 \mathrm{~W}$ is observed from Figure 14. Now, the power from the inverter and grid supplies the load at PCC. This situation creates a deviation in frequency and DC bus voltage. The proposed EIC with HESS control effectively limits the frequency deviation in case of variation in real power setpoint also.

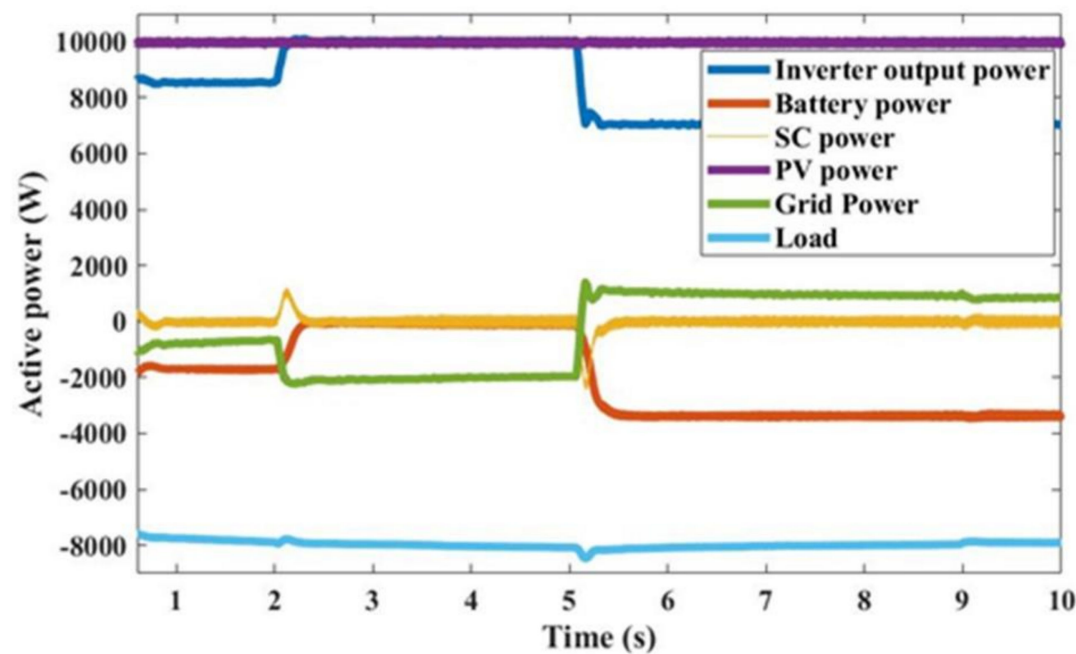

(a)

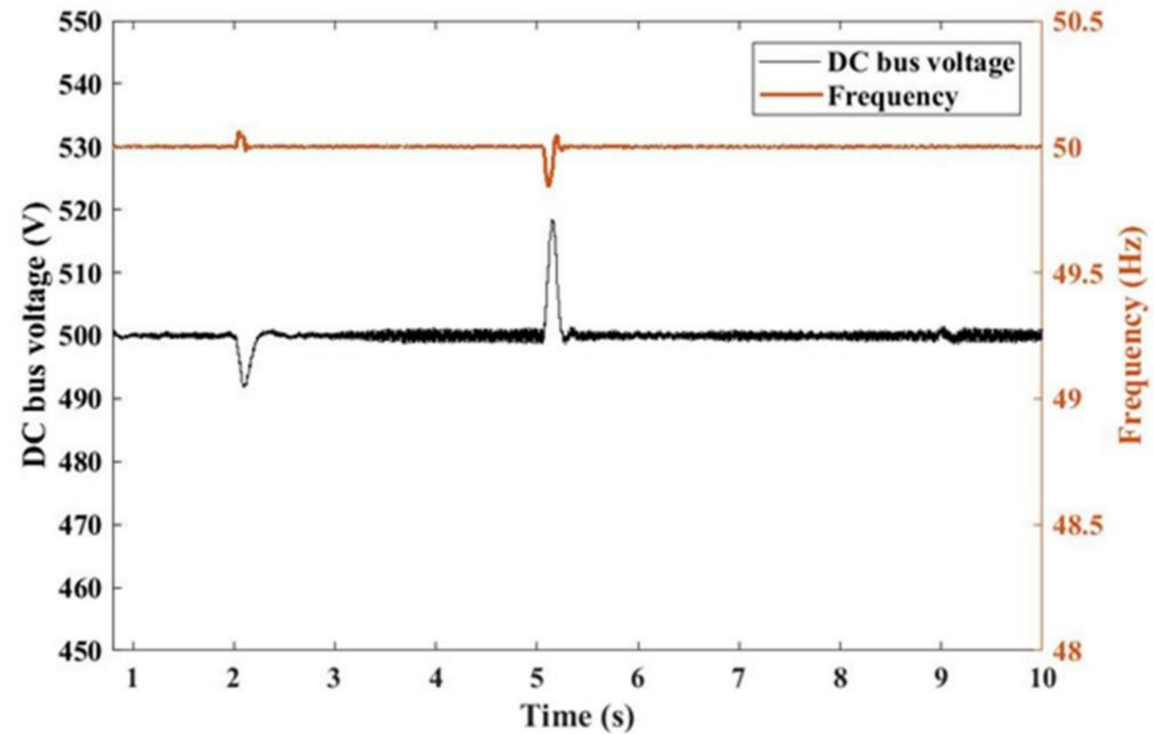

(b)

Figure 14. Real power under grid command variations; (a) Active power (b) DC bus voltage and frequency. 


\subsection{Scenario 3: Performance of Proposed EIC under Variation in PV Power}

The performance of the proposed EIC was evaluated under PV power fluctuations. At first, the PV system is working at irradiation of $850 \mathrm{~W} / \mathrm{m}^{2}$ and the available power from PV system is $8500 \mathrm{~W}$. The active power set point $\left(P_{S e t}\right)$ is assigned as 10,000 W. The PV-HESS system supplies power as per the active power setpoint during irradiation variation. The $\mathrm{PV}$ power varies with irradiation variation then HESS releases or absorbs the real power to offset the power imbalance. The irradiation level of PV is altered to $1000 \mathrm{~W} / \mathrm{m}^{2}$ and $500 \mathrm{~W} / \mathrm{m}^{2}$ at $t=2 \mathrm{~s}$ and $t=5 \mathrm{~s}$, respectively. Figure 15 shows the power variations of different sources (PV, battery, SC, grid). The deficient power is supplied from the HESS system till $t=2 \mathrm{~s}$ to meet the active power set point $\left(P_{S e t}\right)$. At $t=2 \mathrm{~s}$ the maximum power extracted from PV power is increased from $8500 \mathrm{~W}$ to $10,000 \mathrm{~W}$ with an increase in solar irradiation level from $850 \mathrm{~W} / \mathrm{m}^{2}$ to $1000 \mathrm{~W} / \mathrm{m}^{2}$. The power required for the setpoint is supplied by PV system alone till $t=5 \mathrm{~s}$. At $t=5 \mathrm{~s}$, the step decrease in PV power is observed with a decrease in the solar irradiation level from $1000 \mathrm{~W} / \mathrm{m}^{2}$ to $500 \mathrm{~W} / \mathrm{m}^{2}$. The HESS system supplies the deficient power to meet the active power set point $\left(P_{S e t}\right)$ as shown in Figure 15. During this entire change in PV power, it can be observed that the disturbance in the grid power is negligible, and the frequency is smooth as shown in Figure 15b.

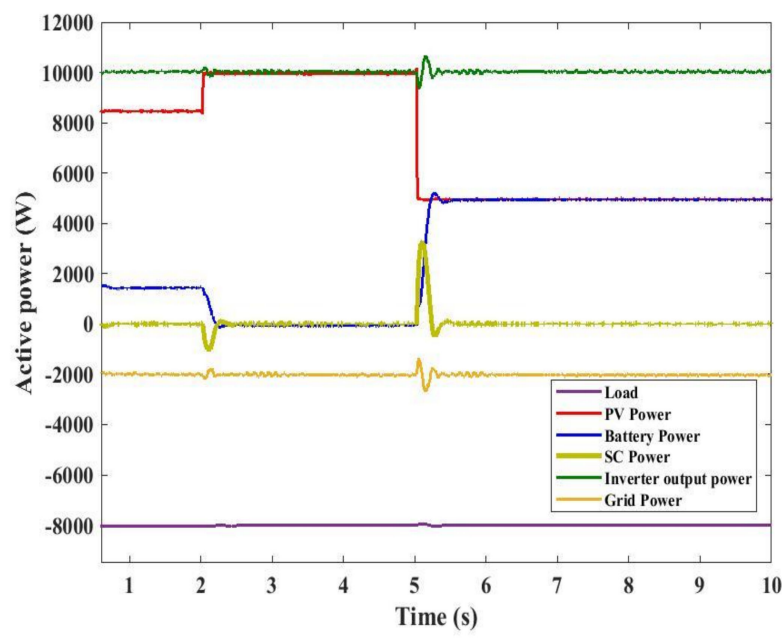

(a)

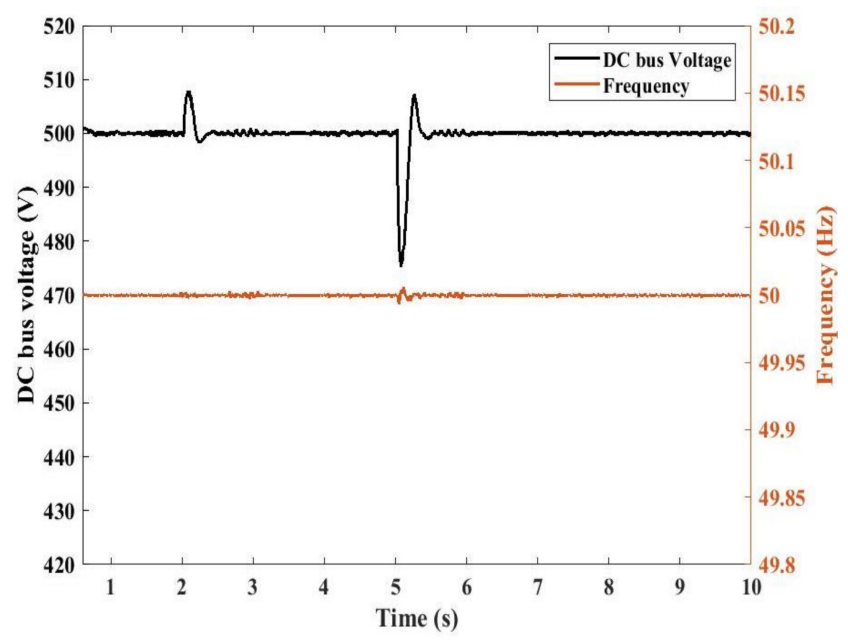

(b)

Figure 15. For PV Power Variation; (a). Different Source active power variations (b) Frequency and DC bus voltage. 


\section{Real-Time Simulation Results}

The OPAL RT real time simulator is fully integrated with RT-LAB MATLAB/Simulink. RT LAB enables Simulink models to interact with the real world in real-time. As a multidomain platform, RT-LAB provides flexible and scalable solutions for the power systems, power electronics, aerospace, and automotive industries. OPAL RT real time simulator is a digital simulator capable of real-time operation, i.e., it can solve the power system equations fast enough to continuously produce output conditions that real-istically represent conditions in the real network. The time step for the simulations and real-time simulations is considered as $10 \mu$ s in the fixed step solver.

To validate the proposed EIC, a grid-connected PV system is tested in two cases. The first case is the load transitions, and the second case is PV power variations. The grid-connected PV-HESS system shown in Figure 1 is dumped into the OPAL RT simulator to test the EIC control. The OPAL-RT setup is shown in Figure 16. The system parameters used in real-time simulations testing are tabulated in Table 1.

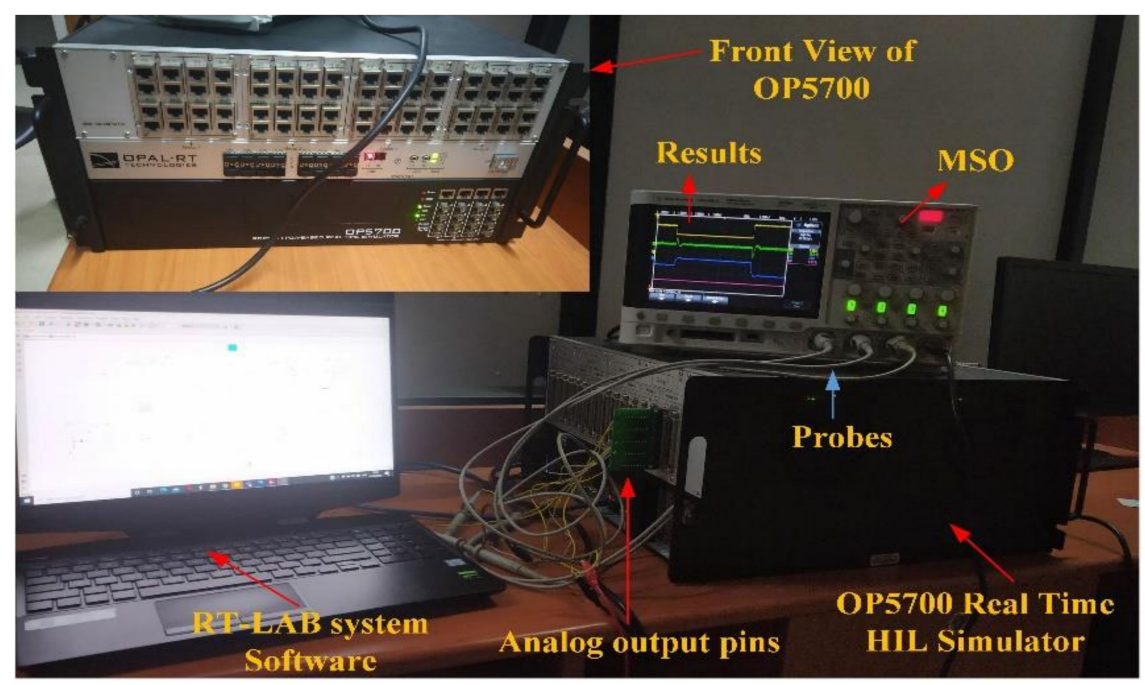

Figure 16. Schematic of OPAL-RT Setup.

\subsection{With Load Transitions}

This scenario analyses EIC's performance for grid-connected PV-HESS system with load variatiosn for constant irradiation and these results are shown in Figure 17. The available power of $10 \mathrm{~kW}$ is extracted from the PV array. The base load of $8 \mathrm{~kW}$ is attached, and the surplus power from PV is exported into grid. Futher, additional demand of $4 \mathrm{~kW}$ is considered at $t=t_{1} \mathrm{~s}$ and results in frequency nadir. As the frequency varies from the reference, the EIC technique triggers and supplies the inertial power. The supplied inertial power is combination of the SC power and battery power. The proposed EIC along with HESS arrests the frequency dip to $49.795 \mathrm{~Hz}$ for a step rise in demand. At $t=t_{2} \mathrm{~s}$ the sudden reduction in demand is modelled, and it creates the frequency variations. As the frequency varies from the reference value, the EIC initiates and absorbs the surplus power. The frequency peak is limited to $50.23 \mathrm{~Hz}$ by the EIC technique for sstep decrease in load, so the EIC governed grid-connected PV-HESS system identical to the SG in frequency regulation. The EIC system adjusts the load angle such that power can be injected/absorbed during frequency variations. Under frequency deviations, the HESS system was modeled so that the highly variable power is supplied/absorbed by the SC, and the battery manages the gradually variable power. 


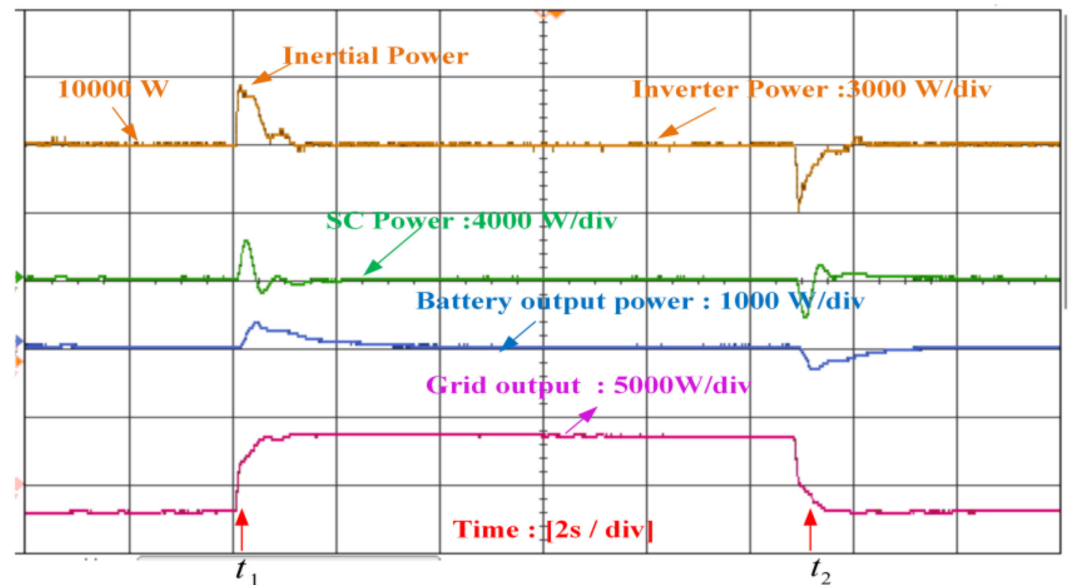

(a)

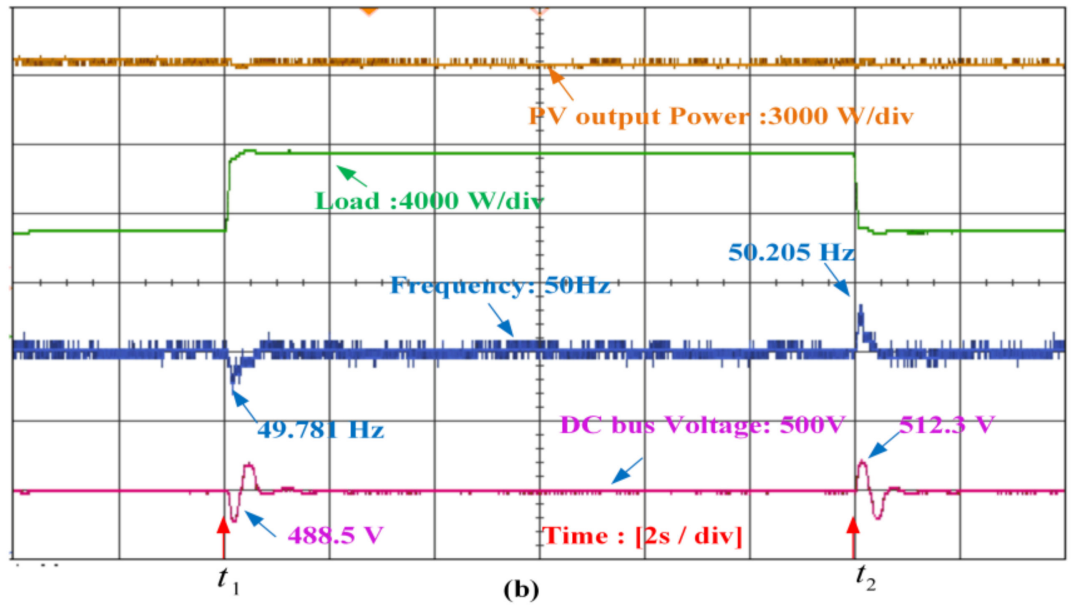

Figure 17. (a) Load variations for constant irradiation (a) power from inverter, SC, battery, and grid; (b) PV Power, load, frequency, and DC bus voltage.

\subsection{With Irradiation Transitions}

This scenario analyses EIC employed grid-connected PV-HESS system under PV irradiation variation. The PV array is runs at an irradiance of $700 \mathrm{~W} / \mathrm{m}^{2}$ and $7.5 \mathrm{~kW}$ is obtained from PV. The base load considered at the PCC is $8 \mathrm{~kW}$. The set value of active power $\left(P_{S e t}\right)$ for the EIC controlled is $10 \mathrm{~kW}$, then the deficient power is delivered by the battery to meet the grid requirement. The step variations in PV irradiation are modelled at $650 \mathrm{~W} / \mathrm{m}^{2}$ and $1000 \mathrm{~W} / \mathrm{m}^{2}$ at $t=t_{1} \mathrm{~s}$ and $t=t_{2} \mathrm{~s}$, correspondingly. The real-time simulation results for variations in PV are illustrated in Figure 18. At $t=t_{1} \mathrm{~s}$, the PV generation reduces with PV irradiation. To meet the set point requirement of EIC technique, the remaining power is supplied by the battery. This transition creates the deviation in DC bus voltage and negligible deviations in the frequency. Grid frequency is stable in this transition because the HESS can handle the sudden decrease in the PV power generation. At $t=t_{2} \mathrm{~s}$ the PV generation rises with PV irradiation level rises to $1000 \mathrm{~W} / \mathrm{m}^{2}$. The power from PV alone is suffiecient to meet the set point. This scenario doesnot impact the frequency, the HESS controller at the DC bus able to handle the PV power variations without affecting the frequency. 

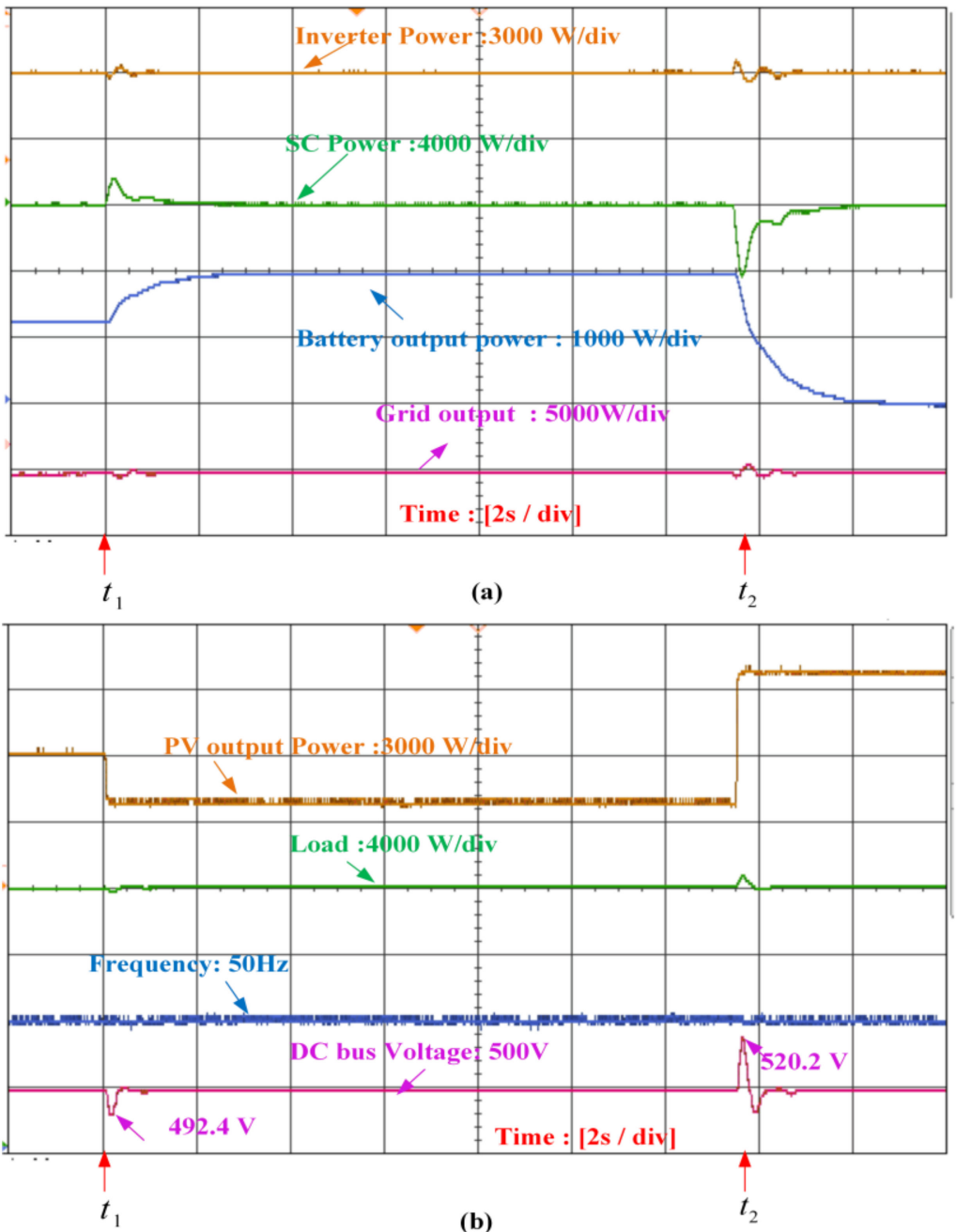

Figure 18. Under irradiation change at base load (a) power from the inverter, SC, battery, and grid; (b) PV power, load, frequency, and DC bus voltage.

\section{Conclusions}

The inertial support provided by the grid-connected PV-HESS system was investigated in this paper. The inertia contribution by HESS with the proposed EIC increases the total grid inertia, reducing the frequency deviation under power imbalances. The selection of super capacitance value for the inertial requirement was discussed. The proportionate power-sharing between the battery and SC is achieved in inertial response with proportionate linking of frequency variations to the DC bus voltage. In load transitions, the SC handles the fast-varying component of the power, and the battery supplies/absorbs the slow-varying component of power to reduce the frequency deviations. Further, a Bode plot evaluation is made to the EIC and HESS controller to prove the stability. The feasibility of the proposed EIC for the grid-connected PV-HESS was verified in simulations and in the real-time simulations using OPAL-RT. The simulation results show significant improvement in the frequency nadir with the proposed EIC and HESS controller compared with the traditional EIC. The real-time simulation results proved that the proposed EIC able to handle the power imbalances in real-time.

Author Contributions: Conceptualization, R.K.S. and P.K.; methodology, R.K.S.; software, R.K.S. and P.K.; validation, Y.T., S.N., H.R.B. and P.K.; formal analysis, R.K.S.; investigation, Y.T., S.N., H.R.B. and P.K.; resources, P.K.; data curation, R.K.S.; writing-original draft preparation, R.K.S.; writing-review and editing, R.K.S.; visualization, R.K.S.; supervision, P.K.; project administration, Y.T., S.N., H.R.B. and P.K.; funding acquisition, P.K. All authors have read and agreed to the published version of the manuscript. 
Funding: This research was funded by Department of Science and Technology (DST)-Government of India, grant number SR/FST/ETI-420/2016(C).

Institutional Review Board Statement: Not applicable.

Informed Consent Statement: Not applicable.

Acknowledgments: Authors like to acknowledge the funding agencies for the supported received for this project activities by Grant Project No. SR/FST/ETI-420/2016(C) "Fund for Improvement of S\&T infrastructure in Universities \& Higher Educational Institutions (FIST)" Department of Science and Technology (DST)-Government of India. Funded to establish the Px set-up which is a part of this research project.

Conflicts of Interest: The authors declare no conflict of interest.

$\begin{array}{ll}\text { Abbreviations } \\ P_{S e t} & \text { Active power reference } \\ P_{C a l} & \text { Active power output } \\ Q_{S e t} & \text { Reactive power reference } \\ Q_{C a l} & \text { reactive power output } \\ D_{P} & \text { Dropping coefficient of frequency } \\ D_{q} & \text { Dropping coefficient of voltage } \\ J & \text { Inertia } \\ k & \text { Constant } \\ \omega & \text { Angular frequency of the system } \\ \omega_{r} & \text { Angular frequency reference } \\ V_{m} & \text { Output voltage of the system } \\ V_{m}^{*} & \text { Reference voltage } \\ \dot{\omega}_{S, \text { max }} & \text { Rate of change of frequency (ROCOF) } \\ H & \text { Inertia constant of SG } \\ H_{S C} & \text { Inertia constant of SC } \\ \omega_{g 0} & \text { nominal angular frequency of the grid } \\ \Delta P & \text { power imbalance. } \\ C_{S C} & \text { capacitance of the SC } \\ V_{S C} & \text { the SC voltage } \\ S_{P V} & \text { The capacity of the PV system } \\ \Delta V_{S C, \text { max }} & \text { The maximum allowed SC voltage variation } \\ \Delta \omega_{g, \text { max }} & \text { The maximum allowed grid frequency variation. } \\ K_{D} & \text { The damping constant, } \\ K_{I} & \text { The inertial constant. } \\ & \end{array}$

\section{References}

1. Zervos, A. Renewables 2018 Global Status Report. Available online: http:/ /www.ren21.net/status-of-renewables/global-statusreport/ (accessed on 7 May 2019).

2. Ratnam, K.S.; Palanisamy, K.; Yang, G. Future low-inertia power systems: Requirements, issues, and solutions-A review. Renew. Sustain. Energy Rev. 2020, 124, 109773. [CrossRef]

3. Sarojini, R.K.; Palanisamy, K. Comparison of Emulated Inertia controller with Synchronous Generator. IOP Conf. Ser. Mater. Sci. Eng. 2020, 937. [CrossRef]

4. Group, W. RoCoF Modification Proposal-TSOs' Recommendations. Available online: http://www.eirgridgroup.com/about/ eirgrid-group/ (accessed on 7 May 2019).

5. Kundur, P.; Balu, N.J.; Lauby, M.G.; Kundur, P.S. Power System Stability and Control; McGraw-Hill: New York, NY, USA, 1994; ISBN 0070635153.

6. Palermo, J. International Review of Frequency Control. Available online: https://www.engineersaustralia.org.au/sites/default/ files/resources/Public\%20Affairs / 2018/Frequency\%20Control\%20Frameworks\%20Review\%20-\%20Engineers\%20Australia\% 20Submission.pdf (accessed on 19 March 2019).

7. Byrne, D. All Island Tso Facilitation of Renewables Studies. Available online: http:/ /www.eirgridgroup.com/site-files/library/ EirGrid/All-Island-SiemensPTI-WP1-091109-part1.pdf (accessed on 8 May 2019).

8. Chen, Y.; Hesse, R.; Turschner, D.; Beck, H. Dynamic Properties of the Virtual Synchronous Machine (VISMA). Proc. Icrepq 11 2011, 1, 755-759. [CrossRef] 
9. Zhong, Q.; Member, S.; Nguyen, P.; Ma, Z.; Sheng, W. Self-Synchronized Synchronverters: Inverters Without a Dedicated Synchronization Unit. IEEE Trans. Power Electron. 2014, 29, 617-630. [CrossRef]

10. Diaz, M.A.; Ramirez, R.; Torres, M.A.; Saavedra, J.; Rohten, J.; Baier, C.R. A virtual synchronous generation strategy for a single-phase grid-connected qZSI. INTELEC Int. Telecommun. Energy Conf. 2019. [CrossRef]

11. Visscher, K.; de Haan, S. Virtual synchronous machines (VSG's) for frequency stabilisation in future grids with a significant share of decentralized generation. SmartGrids Distrib. 2008. IET-CIRED. CIRED Semin. 2008, 1-4. [CrossRef]

12. Sarojini, R.K.; Kaliannan, P. Small Signal Modelling and Determination of Critical Value of Inertia for Virtual Synchronous Generator. In 2019 Innovations in Power and Advanced Computing Technologies (i-PACT); IEEE: Piscataway, NJ, USA, 2019; pp. 1-6.

13. Yan, G.; Liang, S.; Jia, Q.; Cai, Y. Novel adapted de-loading control strategy for PV generation participating in grid frequency regulation. J. Eng. 2019, 2019, 3383-3387. [CrossRef]

14. Hoke, A.F.; Shirazi, M.; Chakraborty, S.; Member, S.; Muljadi, E.; Maksimovic, D. Rapid Active Power Control of Photovoltaic Systems for Grid Frequency Support. IEEE J. Emerg. Sel. Top. Power Electron. 2017, 5, 1154-1163. [CrossRef]

15. Fang, J.; Li, H.; Tang, Y.; Blaabjerg, F. Distributed Power System Virtual Inertia Implemented by Grid-Connected Power Converters. IEEE Trans. Power Electron. 2017, 33, 8488-8499. [CrossRef]

16. Xiong, L.; Zhuo, F.; Wang, F.; Liu, X.; Chen, Y.; Zhu, M.; Yi, H. Static Synchronous Generator Model: A New Perspective to Investigate Dynamic Characteristics and Stability Issues of Grid-Tied PWM Inverter. IEEE Trans. Power Electron. 2016, 31, 6264-6280. [CrossRef]

17. Im, W.S.; Wang, C.; Liu, W.; Liu, L.; Kim, J.M. Distributed virtual inertia based control of multiple photovoltaic systems in autonomous microgrid. IEEE/CAA J. Autom. Sin. 2017, 4, 512-519. [CrossRef]

18. Gonzalez-Longatt, F.M.; Alhejaj, S.M. Enabling inertial response in utility-scale battery energy storage system. IEEE PES Innov. Smart Grid Technol. Conf. Eur. 2016, 605-610. [CrossRef]

19. Brogan, P.V.; Best, R.J.; Morrow, D.J.; McKinley, K.; Kubik, M.L. Effect of BESS Response on Frequency and RoCoF During Underfrequency Transients. IEEE Trans. Power Syst. 2019, 34, 575-583. [CrossRef]

20. Hosseinipour, A.; Hojabri, H. Virtual inertia control of PV systems for dynamic performance and damping enhancement of DC microgrids with constant power loads. IET Renew. Power Gener. 2018, 12, 430-438. [CrossRef]

21. Kamala Sarojini, R.; Palanisamy, K. Emulated Inertia Control for the Stand-Alone Microgrid with High Penetration of Renewable Energy Sources. Int. J. Renew. Energy Res. 2020, 10, 831-842.

22. Zhu, J.; Hu, J.; Hung, W.; Wang, C.; Zhang, X.; Bu, S.; Li, Q.; Urdal, H.; Booth, C.D. Synthetic Inertia Control Strategy for Doubly Fed Induction Generator Wind Turbine Generators Using Lithium-Ion Supercapacitors. IEEE Trans. Energy Convers. 2018, 33, 773-783. [CrossRef]

23. Zhang, R.; Fang, J.; Tang, Y. Inertia Emulation through Supercapacitor Energy Storage Systems. In 2019 10th International Conference on Power Electronics and ECCE Asia (ICPE 2019-ECCE Asia); IEEE: Piscataway, NJ, USA, 2019; Volume 3, pp. 1365-1370.

24. Sarojini, R.K.; Palanisamy, K. Inertia emulation through supercapacitor for a weak grid. IEEE Access 2021, 9, $30793-30802$. [CrossRef]

25. Kollimalla, S.K.; Mishra, M.K.; Narasamma, N.L. Design and analysis of novel control strategy for battery and supercapacitor storage system. IEEE Trans. Sustain. Energy 2014, 5, 1137-1144. [CrossRef]

26. Sarojini, R.K.; Palanisamy, K.; Sanjeevikumar, P.; Nielsen, J.B.H. Inertia emulation control technique-Based frequency control of grid-connected single-phase rooftop photovoltaic system with battery and super-capacitor. IET Renew. Power Gener. 2019, 14, 1156-1163. [CrossRef]

27. Fang, J.; Tang, Y.; Li, H.; Li, X. A Battery/Ultracapacitor Hybrid Energy Storage System for Implementing the Power Management of Virtual Synchronous Generators. IEEE Trans. Power Electron. 2018, 33, 2820-2824. [CrossRef]

28. Ahmed, K.H.; Finney, S.J.; Williams, B.W. Passive Filter Design for Three-Phase Inverter Interfacing in Distributed Generation. Compat. In 2007 Compatibility in Power; IEEE: Piscataway, NJ, USA, 2007.

29. Kotra, S.; Mishra, M.K. Design and stability analysis of DC microgrid with hybrid energy storage system. IEEE Trans. Sustain. Energy 2019, 10, 1603-1612. [CrossRef] 